\title{
OS JOGOS DE ESCALAS NA SOCIOLOGIA DA EDUCAÇÃO*
}

\author{
ZAIA BRANDÃO**
}

RESUMO: A complexidade dos fenômenos sociais indica que uma realidade social não é a mesma dependendo do nível de análise, propóe Revel, em seus "jogos de escalas". O artigo assinala que os dados agregados com os quais se constroem os indicadores socioeconômicos e as escalas de estratificação social com utilização de surveys, centrais para a análise de fenômenos escolares, oferecem certa ilusão de objetividade, pois na vida real posiçóes equivalentes nessas escalas resultam em experiências sociais bastante distintas que só são apreendidas pelo trabalho de campo em nível micro social. Exemplifica uma experiência de pesquisa na perspectiva dos "jogos de escalas" no campo da Sociologia da Educação.

Palavras-chave: Sociologia da Educação. Jogos de escalas. Micro e macro sociologia. Pesquisa em educação.

\section{The game of scales in the Sociology of Education}

ABSTRACT: As argued by Revel in his "games of scales" (Jeux d'échelles), the complexity of social phenomena indicates that $a$ social reality is not always the same, depending on the analysis level. This article emphasizes that the aggregated data used in the construction of socio-economic indicators and scales of social stratification using surveys, central for the analysis of educational phenomena, offer an illusion of objectivity, since equivalent positions on these scales result in very different social experiences in real life, and require fieldwork strategies of research. The text presents the

* Este artigo recebeu apoio da FAPERJ e do CNPq.

** Doutora em Educação e professora do Departamento de Educação da Pontifícia Universidade Católica do Rio de Janeiro (PUC-RIO). E-mail: zaia@puc-rio.br 
example of a research experience in the field of sociology of education from the perspective of the "game of scales".

Key words: Sociology of Education. Game of scales. Micro and macro sociology. Research in education.

V

ma formação superficialmente multidisciplinar nos cursos de Pedagogia tem nos levado a muitos equívocos, quando nos valemos das referências das Ciências Sociais para pesquisar problemas da educação. Um exemplo no campo da História da Educação foi a hegemonização, durante pelo menos uma década, da versão sobre o caráter conservador do movimento da Escola Nova no Brasil. O desconhecimento das discussões historiográficas, que aqueciam o campo da História, impedia-nos de perceber as contradições que atravessavam o processo de profissionalização do campo da educação no início do século xx e a impropriedade da interpretação simplista sobre o significado político-social daquele movimento no Brasil. Minha participação no debate historiográfico sobre a escola nova no Brasil e a familiarização com as alternativas de construção de uma história-problema foram fundamentais para a minha formação de pesquisadora.

Posteriormente, meu encaminhamento para o campo da Sociologia da Educação exigiu um novo investimento em uma socialização disciplinar, que evitasse mais uma vez as armadilhas da "inocência dos educadores" a respeito dos debates conceituais no campo das Ciências Sociais. Fazer escolhas, entre referências teórico-metodológicas em disputa, optando por aquelas mais adequadas aos problemas sob investigação, é o grande desafio que, ainda hoje, enfrenta o campo da educação. Nossa formação pouco embasada nas tradiçóes disciplinares - cujo conhecimento permitiria "o rigor na indisciplina" Soares $(1991)^{1}$ - nos torna com freqüência reféns dos modismos que assolam o campo acadêmico.

\section{A objetividade possível em Ciências Sociais}

Um extenso caminho foi necessário às Ciências Sociais para que as novas gerações de pesquisadores se reencontrassem com a inquietação de Max Weber, ao início do século Xx, sobre as condições de objetividade do conhecimento nas ciências sociais. Este longo processo de reflexão e experimentação de estratégias, na produção de conhecimento sobre o 
mundo social, levou-nos a rever inúmeras hipóteses teóricas e, neste movimento, a revisar o próprio conceito de verdade científica. Teorias são permanentemente postas à prova pelas exigências do mundo empírico, não restando mais espaço para a pretensão das grandes teorias, nem tampouco para a "arrogância da ignorância", denunciada por Bourdieu (1989a), como estratégia "de tornar a necessidade em virtude", ou seja, de escolher uma abordagem por ignorar a forma de operar com outra.

As novas sociologias descritas por Corcuff (1995) são construções de um conjunto de cientistas sociais que, ao longo do século passado, desenvolveram referências teórico-metodológicas que procuravam superar a oposição entre as macrossociologias (estruturas mais amplas) e as microssociologias (unidades sociais menores). $\mathrm{O}$ autor define duas direçôes nestas construções: (a) das estruturas sociais às interaçôes, onde localiza Elias, Bourdieu e Giddens; e (b) das interações às estruturas sociais onde estão situados Berger, Luckmann, Shultz, Cicourel, entre outros. Segundo Corcuff (1995), esses autores cunharam um novo uso da noção de verdade científica - dotada de um caráter mais plural, historicamente situada e provisória - que, no entanto, continue constituindo um "horizonte regulador" do trabalho científico. Ou seja, colocaram em causa as epistemologias binárias - construídas em torno da oposição verdadeiro/falso -, abrindo espaço a uma epistemologia dos domínios de validade para o reconhecimento de proposições enunciadas dentro de regras acordadas na de rigor científico (Corcuff, op. cit., p. 116).

A minha leitura do debate sobre o jogo de escalas, organizado por Jacques Revel, significou um feliz encontro com uma perspectiva (na qual ele se situa) que supera as falsas disputas, ainda hoje bastante fortes na área da educação, entre partidárias das macroanálises e das microanálises, em seus desdobramentos problemáticos na produção dos pesquisadores "quanti" e "quali". Não cabe, nesta intervenção, aprofundar o equívoco das adjetivações de qualitativa ou quantitativa às pesquisas, de livre curso na área de educação. Muito menos retomar o velho e desgastado debate sobre a prioridade ao sujeito ou às estruturas na suposta superioridade ética e/ou política de uma ou outra abordagem. Aqueles que levam a sério as exigências do conhecimento do mundo social há muito passam ao largo desses debates.

Um dos aspectos mais relevantes da posição de Revel no debate sobre o jogo de escalas está no reconhecimento de que uma realidade social 
não é a mesma dependendo do nível de análise. As escalas de observação perspectiva aérea ou do nadador para Elias (1994), de fora e de longe ou de dentro e de perto, segundo Magnani (2005) -, ao oferecerem ângulos diferentes de construção de objetos de pesquisa, não podem ser pensadas como extremos de um mesmo contínuo; pois não se trata de um problema metodológico, e sim de uma impossibilidade epistemológica. A realidade social é por demais abrangente e complexa para comportar a pretensão de um verdadeiro e definitivo olhar, a partir de uma abordagem supostamente mais abrangente. $\mathrm{Na}$ feliz metáfora de Revel, a estrutura folheada do social encontra na variação das escalas um recurso de excepcional fecundidade que possibilita que se construam objetos complexos compatíveis com a descontinuidade dos patamares em que se protagoniza a vida social (Revel, 1998, p. 14).

\section{Desigualdades sociais e desigualdades escolares: os desafios à pesquisa em educação}

Os processos de produção das desigualdades sociais estão no cerne das preocupações das Ciências Sociais e impactam fortemente a pesquisa no campo da Sociologia da Educação. Collins (2000), um dos mais importantes sociólogos americanos, propôs uma reflexão sobre os princípios de "estratificação situacional", a partir da qual problematizou o estatuto de realidade objetiva pretendido pelos levantamentos estatísticos derivados dos surveys. Para ele, as hierarquias desenhadas pela distribuição dos grupos, em categorias ocupacionais, podem ocultar - entre outras variáveis comumente utilizadas nas investigaçôes das desigualdades sociais - diferenças importantes de riqueza, educação.

Os dados agregados com os quais se constroem os indicadores socioeconômicos e as escalas de estratificação social oferecem certa ilusão de objetividade, à medida que na vida real posições equivalentes nessas escalas resultam em experiências sociais bastante distintas. É o caso, por exemplo, de anos ou níveis de escolaridade significando condições de disputa bastante desiguais no mercado de trabalho, conforme o contexto microssituacional. Seis anos de estudo podem significar vantagens adicionais na disputa de um emprego, em uma pequena empresa ou no interior, mas inviabilizar o trabalho em uma multinacional ou numa metrópole.

As escalas de prestígio das ocupações ${ }^{2}$ usuais nos estudos de estratificação social colocam empresários, diretores de empresa, industriais 
e profissionais liberais nos níveis mais elevados. No entanto, nas situações da vida social os padrōes de prestígio dessas posiçôes se atualizam de forma bastante desigual, quer do ponto de vista da deferência, da renda, ou do poder.

Para Collins (2000), as macrodistribuiçóes produzidas pelos surveys devem ser submetidas a uma série de estudos que permitam avaliar as variações a que estão sujeitas nos contextos microssituacionais. Afirma ele:

(...) os dados micro-situacionais têm prioridade conceitual. Isto não quer dizer que os macro-dados nada signifiquem; mas, estatísticas globais e dados de surveys não oferecem um retrato acurado da realidade social, a não ser quando interpretados no contexto de seu enraizamento microsituacional. (Collins, op. cit, n. 18, p.16)

O tema do sucesso/fracasso escolar no Brasil, no campo da Sociologia da Educação, foi durante muito tempo abordado principalmente pela análise de trajetórias escolares. Entretanto, as últimas décadas foram cenário de um significativo avanço na produção de dados macrossociais sobre o desempenho escolar dos sistemas de ensino, oferecendo assim uma outra escala de observação de um dos principais problemas da educação. Entretanto, entre as abordagens de caráter mais fenomenológico (com base nas representações dos atores sociais e utilizando, sobretudo, depoimentos e entrevistas) e as abordagens macrossociais - avaliação de coortes de idades, fluxo de estudantes por sexo, cor ou segmentos (fundamental, médio, superior) - há como que um vácuo empírico, preenchido normalmente mais por inferências residuais dessas perspectivas, do que por análises ancoradas em material empírico específico.

Uma experiência de pesquisa utilizando o jogo de escalas

A pesquisa empírica só tem sentido se admitirmos de antemão que a realidade é mais complexa que a teoria, o que implica, necessariamente, que o trabalho de campo faça surgir novas questôes não contempladas no corpus abstracto geral.

(Teixeira Lopes, 1996, p. 91)

$\mathrm{Na}$ tentativa de fazer a ponte entre estas duas abordagens, o programa de pesquisa do SOCED/PUC-RIO vem estudando os processos de produção da qualidade de ensino em escolas de prestígio na cidade do Rio de Janeiro. 
Numa primeira etapa, fundamentada no escopo teórico da obra de Bourdieu, a equipe desenvolveu um survey composto de três questionários (pais, professores e alunos) com o objetivo de levantar as características mais gerais dos agentes educacionais envolvidos nesses processos. Os questionários foram aplicados nas nove escolas (duas confessionais, duas públicas, duas alternativas e uma judaica). No primeiro momento de exploração dos dados produzidos a partir do survey, focalizamos as características mais gerais dos perfis e das práticas sociopedagógicas dos agentes estudados que nos indicaram a circularidade virtuosa com que as escolas investigadas produziam a imagem de qualidade de ensino destacada anualmente pela mídia. Neste momento, já nos chamavam a atenção certas características diferenciais entre as instituições, que exigiriam para uma melhor compreensão um outro nível de abordagem.

O retorno ao campo em três dessas escolas (uma confessional, uma alternativa e uma pública) ofereceu-nos condições de contrastar o perfil geral delineado a partir dos dados agregados, com o material empírico derivado da observação do cotidiano escolar em sua dinâmica situacional. De dentro e de perto, as dimensōes materiais e simbólicas dos contextos educacionais compóem outras imagens sobre as redes de interações (verticais e horizontais) com que as escolas investigadas produzem a imagem de qualidade de ensino.

Construímos assim outro corpus empírico com condições de esboçar conjuntos de valores e formas de desenvolvimento do currículo com que cada instituição desenvolve as "habilidades escolares", que consolidam estilos e disposições cognitivas diferenciadas que operam como selos da escolaridade nas diferentes instituições. Estes selos são reconhecidos no mercado escolar e adquirem valores sociais e simbólicos distintos, que não são visíveis nas análises de desempenho escolar produzidas pelos surveys educacionais.

Procuramos delinear a auto-imagem institucional (representaçōes dos estudantes, pais, direção, professores e equipes pedagógico-administrativas), os organogramas reais traçados a partir do fluxo das ações dos agentes institucionais, as lideranças e estilos de gestão, o clima escolar, as práticas curriculares e a distribuição do tempo escolar, a utilização de espaços específicos - como bibliotecas, laboratórios, salas ambientes, auditório, capelas etc. -, as relaçôes interinstitucionais, os trabalhos sociais com as comunidades próximas, as atividades extracurriculares e as estratégias 
de divulgação da imagem institucional (nas páginas das escolas na internet, em folhetos, na mídia...) etc.

Temos operado assim de forma a combinar um olhar mais geral com outro mais próximo, potencializando a ampliação do corpus da pesquisa a partir das novas hipóteses geradas pelo material derivado de um jogo de escalas (Revel, 1998). Este trânsito entre escalas de observação exigiu, inclusive, uma reavaliação das referências teórico-metodológicas com as quais temos trabalhado (marcadamente dentro da tradição da sociologia de Bourdieu) e levou-nos a recompor o desenho teórico-metodológico da investigação, para que respondesse melhor à aproximação das configurações socioeducativas das escolas. Para essas análises institucionais não recusamos, como Bourdieu, uma interlocução com a tradição interacionista (Goffman, Becker, assim como, mais recentemente, Teixeira Lopes). Entretanto, procuramos não desconhecer os contextos sócio-hierárquicos em que se desenvolvem as interaçôes sociais.

Nesse sentido, e mantendo a riqueza da tensão inerente ao jogo de escalas, nosso horizonte teórico-metodológico se orientou por um ecletismo controlado que permitisse transitar pelas perspectivas delineadas pelo jogo de escalas e oferecesse condições de construir interpretaçóes mais flexíveis e densas sobre a ação educativa das escolas.

Durante todo o processo de investigação, temos alternado numa espécie de jogo de espelhos o foco de análise, do âmbito micro ao macrossocial, projetando:

- ora uma visão panorâmica das posiçóes relativas das instituições no campo escolar e no espaço social (Bourdieu) que contribua para a compreensão/interpretação das suas estratégias no mercado escolar;

- ora uma aproximação das lentes em condições de delinear com maior precisão as motivações e os movimentos dos agentes educativos nos tempos e espaços escolares (perspectivas interacionistas).

Os dados construídos a partir do survey são relacionados com dados mais gerais produzidos pelo sistema de avaliação do INEP (SAEB, ENEM, entre outros), sempre que estas comparações ajudam a elucidar as especificidades dos casos estudados. Neste caso, a abordagem relacional com todo o equipamento conceitual proposto por Bourdieu e as referências sobre 
estratificação e mobilidade social no Brasil, dos trabalhos de Pastore e Silva (2000), continuam válidas para a interpretação dos aspectos distintivos dos perfis agregados dos agentes e instituiçôes.

As características das práticas pedagógicas e desempenho dos alunos em uma turma, uma escola ou em um sistema escolar seguramente têm sido bem delineadas pelos surveys e podem ser analisadas em sua relativa autonomia em cada uma dessas instâncias; o desenvolvimento dos modelos multiníveis de análise estatística tornou-se importante instrumento no refinamento do trabalho com os macrodados. Possibilita abordar de maneira adequada o caráter hierarquizado (não aleatório) da distribuição dos alunos, turmas e escolas pelos subsistemas escolares (municipal, estadual, privado). Apesar de todos esses avanços, a análise dos processos escolares na perspectiva da estratificação situacional proposta por Collins continua a ser instrumento fundamental para uma compreensão mais densa dos processos de produção de qualidade de ensino.

No caso do trabalho de campo, como já indicado, é na tradição interacionista da Escola de Chicago e, sobretudo, na perspectiva das interaçôes simbólicas e da metáfora teatral de Goffman que procuramos analisar as redes de interação institucionais (direção/coordenações, assim como professores/funcionários, professores/alunos, alunos/alunos e pais/ escola...). Os resultados do programa de Pesquisas do SOCED são divulgados semestralmente no Boletim SOCED on-line, ${ }^{3}$ desde 2005.

\section{O processo de redimensionamento do núcleo teórico}

\section{(...) as teorias são programas de pesquisa que requerem, não o "debate teórico", mas a sua utilização prática capaz de as refutar ou de as generalizar, ou melhor, de especificar e de diferenciar sua pretensão à generalidade.}

(Bourdieu, 1992, p. 56-7)

A obra de Bourdieu tem sido, como assinalamos, uma referência central para aqueles que, como nós, investem em trabalhos de pesquisa em que teoria e empiria encontram-se profundamente articuladas. Não concebemos, no entanto, um primeiro momento de construção de um "quadro teórico", ao qual sucedeu um trabalho de campo coerentemente articulado à visão teórica adotada. Muito pelo contrário, temos desenvolvido a estratégia sugerida por Bourdieu que implica trabalhar com e 
contra os autores (e teorias), a partir de um processo em que o objeto de investigação é construído através de uma espécie de quebra-cabeça teórico-empírico e, portanto, exige uma reconstrução teórica ad hoc consistente com os problemas que surgem do campo.

Norbert Elias é outra referência indispensável para pensar a matriz relacional a partir da qual se constrói a vida social, e nela as instituições. Seu clássico ensaio, A sociedade dos indivíduos, publicado em 1937 - discorrendo sobre o equívoco das perspectivas unilaterais para apreender o fluxo do mundo social -, tem sido amplamente retomado pelos sociólogos contemporâneos numa demonstração inequívoca da pertinência do seu enfoque para a compreensão da complexidade do tecido social. Segundo ele, um dos maiores limites ao avanço do conhecimento social era a ausência de modelos conceituais que permitissem compreender de que modo um grande número de indivíduos compóe entre si algo maior e diferente de uma coleção de individuos isolados (o princípio durkheiminiano), ou seja, como se estabelecem os vínculos entre os indivíduos e a sociedade.

A teoria da Gestalt já oferecera um forte argumento a respeito de como o todo incorpora princípios que não podem ser delineados pelo exame das partes isoladamente. Um conjunto de jovens em uma sala de aula (turma) constitui uma realidade social diferente de um grupo de jovens numa competição esportiva ou numa reunião social. Os agentes sociais em uma instituição escolar também formam um corpo social com características singulares que não podem ser desenhadas a partir da mera agregação dos indivíduos, nem mesmo dos subgrupos que formam a instituição turmas, coordenaçōes, corpo docente, equipe técnico-administrativa etc.

A interdependência das pessoas na teia social é tratada por Elias como uma cadeia ininterrupta de ações que associam os indivíduos em uma trama complexa de relações, ligando-os a diversos grupos, os quais, por sua vez, podem ser interdependentes ou não. É esse conjunto de possibilidades de ligaçôes, significativamente diferentes, que confere uma flexibilidade às relações sociais que muitas vezes dá a ilusão de poderem ser compreendidas na dinâmica (restrita) das interações face a face, próprias às abordagens interacionistas, supondo a essas um grau de autonomia que dificilmente elas podem alcançar.

Os dois autores - Bourdieu e Elias - formam as referências teórico-metodológicas mais gerais, a partir das quais temos ousado caminhar na direção de um ecletismo controlado que dê conta dos desafios 
postos pelo jogo de escalas com o qual temos desenvolvido o programa de pesquisas do SOCED, produzindo um material empírico diversificado para a formulação de hipóteses sobre a constituição dos habitus escolares nas instituições investigadas.

No interior das diferentes instituições, os indivíduos desempenham funções distintas e simultâneas ${ }^{4}$ - constituem-se como subjetividades coletivas e constituem-nas em coletividades específicas -, num processo permanente de interinfluências: impondo a sua presença (acrescentando-se ao grupo, influindo na dinâmica coletiva) e submetendo-se às forças do grupo (representaçôes, práticas, hábitos, regras de convívio...). As abordagens interacionistas, que estão longe de significar um conjunto homogêneo, foram de fundamental importância para o desenvolvimento das análises dos microssistemas. Weber já havia acentuado, em seus ensaios de sociologia compreensiva, a atividade social como comportamento significativo orientado pelos outros. As significações devem ser partilhadas para que as atividades sejam reguladas, e esta partilha se efetua a cada vez, em situações particulares. Analisar interaçôes implica a análise das microssituaçôes nas quais elas ocorrem, procurando compreender o contexto simbólico e material que as sustenta e que, normalmente, deixa uma boa margem à improvisação, o que exige uma permanente atenção para as peculiaridades de cada caso estudado.

Trabalhamos, no entanto, cientes a respeito dos limites das perspectivas interacionistas. Elas podem subestimar o papel relativamente autônomo que podem ter as estruturas na definição das condiçôes (sociais) em que se realizam as interações (Durand \& Weil, 1989, p. 180). Coser (1975, apud Durand \& Weil, 1989) critica a tendência das abordagens interacionistas de se limitarem à observação direta dos quadros interativos, negligenciando os fatores latentes em favor dos conteúdos manifestos. Ele ressalta que a verdade da interação não é dada pela própria interação, pois os agentes ocupam posições em um espaço objetivo de propriedades em que determinadas regras se impõem a eles. Não se pode reduzir uma poeira de atividades individuais a um todo coerente, recusando-se a analisar o efeito de imposição do poder assegurado pela mediação das instituições (idem, ibid., p. 181).

Somente operando com um permanente jogo de espelhos, que ofereça um conjunto de flashes descontínuos das escalas de observação, pode a Sociologia da Educação enfrentar o desafio de compreender as relações 
entre desigualdades sociais e desigualdades escolares para quiçá traçar estratégias mais adequadas ao projeto de qualidade de ensino com equidade social.

Recebido em novembro de 2007 e aprovado em abril de 2008.

\section{Notas}

1. Soares (1991) fala da importância do domínio disciplinar como condição para "saltar” as fronteiras disciplinares nas tentativas de desenvolver diálogos interdisciplinares.

2. Ver, a respeito, Araújo \& Scalon (2005), Ribeiro (2007), Santos (2002).

3. O leitor pode consultar os cinco números do Boletim SOCED no endereço: <www.soced.pro.br>

4. Como, por exemplo, filhos/alunos, pais/professores, colegas/alunos, professor/coordenador etc.

\section{Referências}

ARAÚJO, C.; SCALON, C. (Org.). Gênero, família e trabalho no Brasil. Rio de Janeiro: FGV, 2005.

BOURDIEU, P. A reprodução. Rio de Janeiro: Francisco Alves, 1975.

BOURDIEU, P. La distintion. Paris: Minuit, 1979.

BOURDIEU, P. Homo academicus. Paris: Minuit, 1984.

BOURDIEU, P. O poder simbólico. Rio de Janeiro: DIFEL, 1989a.

BOURDIEU, P. La noblesse d'État. Paris: Minuit, 1989b.

BOURDIEU, P. Coisas ditas. São Paulo: Brasiliense, 1990.

BOURDIEU, P. (Dir.). La misére du monde. Paris: Seuil, 1993.

BOURDIEU, P. Razões práticas. Campinas: Papirus, 1996.

BOURDIEU, P. ; WACQUANT, L.J.D. Réponses. Paris: Seuil, 1992.

BRANDÃO, Z. Fluxos escolares e efeitos agregados pela escola. Em Aberto, Brasília, DF, v. 17, p. 41, 2000.

BRANDÃO, Z. A dialética micro/macro na Sociologia da Educação. Cadernos de Pesquisa, São Paulo, n. 113, p. 153-165, 2001. 
BRANDÃO, Z. Clima escolar: notas de campo de três visitas a escolas. Boletim SOCED, Rio de Janeiro, n. 2, p. 1-19, 2005.

BRANDÃO, Z. Desatenção ou novos estilos de cognição? Boletim SOCED, Rio de Janeiro, n. 1, p. 1-8, 2005.

BRANDÃO, Z. A pesquisa em educação: o olhar do nadador: do individual ao coletivo. Educação On-Line, Rio de Janeiro, v. 1, p. 1-15, 2005.

BRANDÃO, Z. Elites escolares e capital cultural. Boletim SOCED, Rio de Janeiro, n. 3, 2006.

BRANDÃO, Z. A produção das elites escolares. Educação On Line, Rio de Janeiro, n. 2, 2006.

BRANDÃO, Z.; ALTMAN, H. Algumas hipóteses sobre a transformação dos habitus. Boletim SOCED, Rio de Janeiro, n. 1, p. 1-12, 2005.

BRANDÃO, Z.; CARVALHO, C.; CAZELLI, S. A elite docente na produção da qualidade de ensino. Boletim SOCED, Rio de Janeiro, n. 1, p. 1-19, 2005.

BRANDÃO, Z.; LELIS, I. Elites acadêmicas e escolarização dos filhos. Educação \& Sociedade, Campinas, v. 24, n. 83, p. 509-526, ago. 2003.

BRANDÃO, Z.; MANDELERT, D.; PAULA, L. A circularidade virtuosa: investigação sobre duas escolas no Rio de Janeiro. Cadernos de Pesquisa, São Paulo, v. 35, n. 126, p. 747-758, set./dez. 2005.

BRANDÃO, Z.; VARGAS, H . Escola alternativa. Boletim SOCED, Rio de Janeiro, n. 3, 2006.

BRESSOUX, P. Les recherches sur les effets-écoles er les effets-maîtres. Revue Française de Pédagogie, Paris, n. 108, p. 91-137, juil./sept. 1994.

CARVALHO, C.P. Entre as promessas da escola e os desafios da reprodução social: famílias de camadas médias do ensino fundamental à universidade. 2004. Tese (Doutorado) - Departamento de Educação, Pontifícia Universidade Católica do Rio de Janeiro, Rio de Janeiro.

COLLINS, R. Situational stratification: a micro-macro theory of inequality. Sociological Theory, San Francisco, v. 18, n. 1, p. 16-43, 2000.

CORCUFF, P. Les nouvelles sociologies. Paris: Nathan, 1995. 
COUSIN, O. Politiques et effets-établissements dans l'enseignement secondaire. In: VAN Zanten, A. (Dir.). L'école l'état des saviors. Paris: La Découverte, 2000. p.139-148.

DEROUET, J. L.; VAN ZANTEN, A.; SIROTA, R. Approches ethnographiques en sociologie de l'éducation: l'école et la communauté, l'établissement scolaire, la classe. In: INSTITUT NATIONAL DE RECHERCHE PEDAGOGIQUE (INRP). Sociologie de l'éducation: dix ans de recherché ; recueil de notes de synthèse publiées par la Revue Française de Pédagogie. Paris: Harmattan, 1990.

DORTIER, J.F. (Dir.). Dictionaire de sciences humaines. Auxerre, FR: Sciences Humaines, 2004.

DURAND, J.P.; WEIL, R. Sociologie contemporaine. Paris: Vigot, 1989. DURU-BELLAT, M.; VAN ZANTEN, A. Sociologie de l'école. Paris: Colin, 1999.

ELIAS, N. A sociedade dos individuos. Rio de Janeiro: Zahar, 1994.

HALSENBALG, C.; SILVA, N.V. Origens e destinos: desigualdades sociais ao longo da vida. Rio de Janeiro: FAPERJ; Topbooks, 2003.

LAHIRE, B. Tableaux de familles. Paris: Gallimard; Seuil, 1995.

LEE, V. et al. Catholic schools and common good. Cambridge, MA: Harvard University, 1996.

LOPES, J.T. Tristes escolas. Lisboa: Afrontamento, 1996.

MAGNANI, J.G.C. De perto e de dentro: notas para uma etnografia urbana. Revista Brasileira de Ciências Sociais, São Paulo, v. 17, n. 49, p. 11-29, 2002.

MAYER, N. Analyse critique de La misère du monde. Révue Française de Sociologie, Paris, v. 36, p. 335-370, 1995.

MONTANDON, C. L'école dans la vie des familles. Genève: Service de la Recherche Sociologique, 1991. (Cahier, n. 32).

MONTANDON, C.; PERRENOUD, P. Entre parents et enseignants: un dialogue possible? Berne: Peter Lang, 1987. 
NOGUEIRA, M.A. Trajetórias escolares, estratégias culturais e classes sociais: notas com vistas à construção de um objeto de pesquisa. Teoria \& Educação, Porto Alegre, n. 3, p. 89-112, 1991.

NOGUEIRA, M.A. Elementos para uma discussão da relação classes médias/escola. In: Veiga-Neto, A.J. (Org.). Sociologia da educação. Porto Alegre: ANPEd, 1994. p. 131-145.

NOGUEIRA, M.A.; CATANI, A. (Org.). Bourdieu, P. Escritos de educação. Petrópolis: Vozes, 2003.

PASTORE, J.; SILVA, N.V. Mobilidade social no Brasil. São Paulo: Makron, 2000.

POUPART, J. Discours et débats autour de la scientificité des entretiens en recherche. Sociologies et Societés, Montreal, v. 25, n. 2, p. 93-110, 1993.

REVEL, J. Jogos de escalas: a experiência da microanálise. Rio de Janeiro: FGV, 1998.

RIBEIRO, C.A.C. Estrutura de classe e mobilidade social no Brasil. Bauru: EDUSC, 2007.

SANTOS, J.A.F. Estrutura de posiçôes de classe no Brasil. Belo Horizonte: UFMG; Rio de Janeiro: IUPERJ, 2002.

SILVA, N.V ; HASENBALG, C. (Org.). Origens e destinos: desigualdades sociais ao longo da vida. Rio de Janeiro: Top Books, 2003.

SOARES, L. E. Faça a coisa certa: o rigor da indisciplina. In: BIRMAN, P.; Bomeny, H. As assim chamadas Ciências Sociais. Rio de Janeiro: UERJ; Relume Dumará, 1991. p. 265-277.

TERRAIL, J-P. La dynamique des générations. Paris: L' Harmattan, 1995.

VAN ZANTEN, A. (Dir.). L'école, l'état des savoirs. Paris: La Découverte, 2000 .

WEBER, M. Ensaios de sociologia. 4. ed. Rio de Janeiro: Zahar, 1979. 